TITLE PAGE

\title{
Lessons from latrogenic Cushing Syndrome in Children
}

\section{(Instructive Case)}

$\underline{\text { AUTHORS }}$

Betty P-Messazos MBBChir, BSc (Hons), MA, MRCPCH

Margaret R Zacharin DMedSci BS FRACP

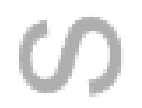

Department of Endocrinology and Diabetes, Murdoch Children's Research Institute

Royal Children's Hospital,

$\underline{50 \text { Flemington Road, Parkville }}$

Victoria 3052, Australia

\section{Corresponding Author:}

Betty Messazos

$=$

Department of Endocrinology and Diabetes, Royal Children's Hospital

$\underline{50 \text { Flemington Rd, Parkville } 3052 \text { VIC, Australia }}$

\section{betty.messazos@rch.org.au}

This is the author manuscript accepted for publication and has undergone full peer review but has not been through the copyediting, typesetting, pagination and proofreading process, which may lead to differences between this version and the Version of Record. Please cite this article as doi: $10.1111 /$ jpc.13273

This article is protected by copyright. All rights reserved. 
The authors declare no conflicts of interest in relation to this manuscript.

Word count 1324

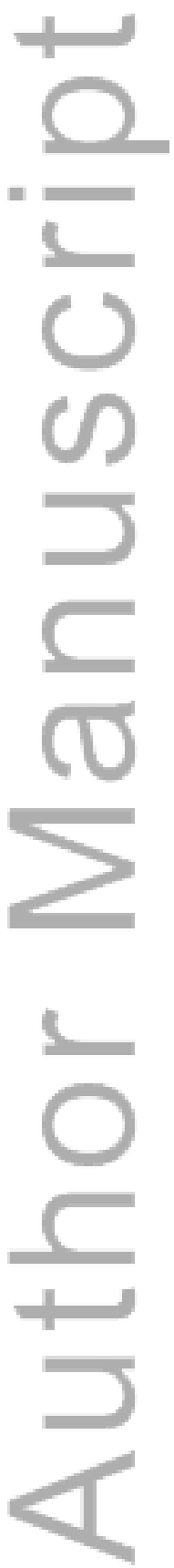

This article is protected by copyright. All rights reserved. 


\section{Key Learning Points}

The learning objectives of this clinical vignette are to describe challenges faced in managing children and adolescents with chronic corticosteroid requiring disorders, by discussing

1. Adverse effects specific to paediatrics, associated with long term high dose corticosteroid treatment

2. The potential pitfalls in assessment of a child using chronic high dose corticosteroids.

3. A constellation of characteristic management issues unique to paediatrics, associated with high dose exogenous corticosteroid use.

\section{Introduction}

Several challenges arise when considering paediatric use of long standing corticosteroids in addition to universal problems associated with steroid withdrawal, including relapse of the underlying chronic condition, ongoing suppression of the hypothalamic pituitary axis (HPA), delayed or slow recovery from adrenal insufficiency and psychologic effects of corticosteroid withdrawal, including depression and psychosis $(1,2)$

Children have additional issues to address, including suppression of growth leading to short stature and reduced final height potential and possible arrest or failure of pubertal onset or progress. Bone health is a particular problem, with failure of accrual of optimal adult bone mass (2).

\section{Case Report}

Presentation: A boy diagnosed at age 7 years with nephrotic syndrome presented at age 14 for assessment of short stature. 
Past history: Nephrotic syndrome was initially treated with unknown doses of prednisolone for 2 years, then with Ayurvedic medications (a form of complementary and alternative medicine that originated in India and remains part of traditional health care) for 5 years. He also had intermittent courses of corticosteroids for four relapses of steroid sensitive nephrotic syndrome (SSNS). His parents were concerned about his height and preferred using 'naturopathic' medicines.

Six months preceding presentation with apparent relapse to our hospital emergency department, the family reported addition of an extra tablet per day, the nature of which was not known to them. It was associated with $10 \mathrm{~kg}$ weight gain, increasing lethargy, excessive hair growth, peripheral oedema, further slowing of growth, low mood, sleep and behavioural disturbances.

Examination: Revealed a profoundly Cushingoid appearance (Fig 1), height $142.1 \mathrm{~cm}$, $\left(<1^{\text {st }}\right.$ centile), weight $51 \mathrm{~kg}\left(50^{\text {th }}\right.$ centile), BMI $25.3 \mathrm{~kg} / \mathrm{m} 2$ (Z: $\left.+1.50 \mathrm{SD}\right)$ [Mid-parental height $(\mathrm{MPH}) 178 \mathrm{~cm}\left(60^{\text {th }}\right.$ centile $\left.)\right]$. Features included truncal obesity, rounded plethoric facies, dorsocervical adipose tissue, hypertrichosis, gynaecomastia, pigmented abdominal striae. He was prepubertal with $3 \mathrm{ml}$ testes bilaterally and stage 2 pubic hair.

Investigations: Lateral thoracolumbar spine radiograph demonstrated multiple crush fractures (Fig 3).Rachitic features were absent. Height adjusted bone mineral density (BMAD) was -2.5SD at lumbar spine and $-3.2 \mathrm{SD}$ at hip. Bone age was $11.5 \mathrm{yrs}$ Biochemistry revealed low morning cortisol 9mmol/L (NR200-750), ACTH <0.3pmol (NR $<20 \mathrm{pmol} / \mathrm{L}$ ), undetectable androgens and vitamin D 35nmol/L (NR >50 $\mathrm{nmol} / \mathrm{L})$. Urine steroid profile gas liquid chromatography (GLC) demonstrated very low steroid metabolites but high urinary free cortisol at 1686nmol/day $(N R<150)$, consistent with exogenous prednisolone measured in the assay. A very large peak of unidentified steroid was seen on the gas liquid chromatography profile, not identifiable using our existing steroid library. Lipids were normal. Urine protein:creatinine ratio was not in the nephrotic range.

Assessment and management: Cushing syndrome secondary to excessive exogenous corticosteroid was diagnosed. Rapid reduction of corticosteroid to $10 \mathrm{mg} / \mathrm{m} 2 /$ day of 
prednisolone was followed by a slower reduction to allow recovery of the HPAaxis and to allow ongoing assessment for possible relapse of nephrotic syndrome. Amlodipine was commenced for treatment of hypertension and vitamin D deficiency was treated. Multiple vertebral fractures were treated with bisphosphonate as Zoledronic acid every 4months. Serial photography and growth chart illustrate progressive improvement of appearance and growth parameters. (Figs 1\&2)

\section{Discussion}

Our patient had classic signs of corticosteroid excess. Despite the family perception of receiving 'natural therapies', his height and multiple vertebral fractures are at odds with this. Multiple fractures and Cushingoid appearance can both occur within six months of high dose corticosteroid. A longer duration of iatrogenic corticosteroid excess is suggested by his extreme short stature for mid-parental expectation. Historically he became acutely Cushingoid over the 6 months prior to presentation, confirmed by photographic evidence of altered appearance. It is also possible that the Ayuverdic therapies may have contained corticosteroid, unfortunately a recognized event and/or that previous corticosteroid intermittent courses had been prolonged or of high dose. We were unable to confirm precise duration or dosing schedules with the family. In this situation, consecutive family photographs can help identify subtle changes, as in the case. During childhood simultaneous increase in weight gain accompanied by reduction in height velocity is suspicious for corticosteroid excess or hypothyroidism (Fig 2). Typical facial features of corticosteroid excess may not be as obvious as in adults. Striae are often absent, with better elasticity of a child's skin. Hypertension is not common however back pain, muscle weakness, hirsutism and tiredness are common $(1,3)$.

Withdrawal from corticosteroids in a child with a chronic disease process presents significant challenges. In our patient the following issues were important to consider:

\section{Recurrence of nephrotic syndrome.}


Risk of relapse must be balanced against corticosteroid side effects. Options of other immunosuppressants need be considered. Our patient's SNNS relapsed as corticosteroid was reduced, but was subsequently controlled with cyclophosphamide.

\section{Possible continuing adrenal suppression (AS)}

Adrenal suppression secondary to exogenous corticosteroid is the most common cause of adrenal insufficiency (4). Full recovery can usually be expected but the HPA-axis may remain suppressed for many months, reported up to a median of 11 months but with very little data reported (7). Supportive education to reduce the risk of potentially life threatening adrenal crisis is essential. The North American Pediatric Endocrine Society (PES) recommends AS be considered in all children who have received supraphysiological doses of corticosteroids ( $>8-12 \mathrm{mg} / \mathrm{m} 2 /$ day hydrocortisone or equivalent) for $>2$ weeks. Children who develop clinical features of corticosteroid excess are at higher risk of experiencing AS. A careful weaning process should be followed if on sypraphysiological doses for $>2$ weeks (3). Alternative testing for normalization of the HPA has been suggested including standard or low dose synacthen tests (8).

\section{Growth Suppression}

Children exposed to prolonged, high doses of corticosteroids are at risk of growth suppression, pubertal delay/arrest and poor bone mass accrual, in addition to the well recognised side effects of bone loss and weight gain. Endocrine effects of corticosteroids include: disruption in the GH-IGF1 axis, direct effects on the growth plate, reduced endocortical bone accrual, altered expression of genes regulating bone turnover (RANKL, $\mathrm{OPG}$ ), reduced vitamin $\mathrm{D}$ action on calcium absorption and renal calcium reabsorption, decreased adrenal androgens and gonadotrophin secretion, and secondary hyperparathyroidism $(2,5)$. Management adjustment to avoid excess corticosteroid has provided better linear growth and reduced disfiguring side effects.

\section{$\underline{4 . \text { Bone Health }}$}


Fifty percent of lifetime bone mass is accrued during puberty, Therefore these years are of particular importance for skeletal integrity. A combination of poor cortical bone mass and decreased trabecular mineralization increase long bone and vertebral crush fracture risk. Failure to accrue bone, seen by increasing BMD of 2-5\% per annum before puberty and $10-15 \%$ pa during puberty alerts the paediatrician to pro-actively plan interventions (5). Adequate management with calcium, vitamin $D$, weight bearing exercise is essential, with age appropriate pubertal induction if needed. The only other currently available modality to protect the skeleton in paediatric and adolescent years is bisphosphonate (6). Use of this group of drugs should be limited to deteriorating bone mass and/or axial (vertebral) or minimal trauma, appendiceal fracture in the face of normalizing all other available parameters as outlined above $(2,6)$.

\section{Steroid withdrawal syndrome}

Corticosteroid excess is associated with well recognised psychiatric and cognitive disturbances, including working memory alteration, anxiety, insomnia, mood lability and psychosis. Importantly, significant psychopathology can remain even after remission and HPA recovery. Early detection is important $(1,3)$.

\section{Summary}

Children suffering chronic illness and who are treated with corticosteroids have specific health risks. In addition to the well recognised corticosteroid side effects, paediatricians should be aware of additional hazards of linear growth failure, delayed or arrested puberty with consequent failure of bone mass accrual with increased risk of vertebral and long bone fracture. Appropriate interventions to minimise corticosteroid dose, supplementation with calcium and vitamin $\mathrm{D}$, pubertal induction and bisphosphonate where required, reduce morbidity and improve outcome.

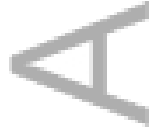

\section{MULTIPLE CHOICE QUESTIONS}




\section{QUESTION 1}

Growth failure associated with Cushing Syndrome in the growing child may be due to:

a) High dose corticosteroid use

b) Multiple crush fractures

c) Chronic illness

d) Pubertal delay

e) All of the above

\section{ANSWER 1}

E. All of the above contribute to growth failure and are very important parameters to consider in the assessment and management in paediatric Cushing syndrome.

\section{QUESTION 2}

Which of the following is correct?

a) Peak bone mass accrual occurs during puberty

b) Peak bone mass accrual occurs post puberty

c) Peak bone mass accrual occurs in mid childhood

d) Peak bone mass accrual is independent of gonadotrophins

e) Linear growth is not affected by chronic corticosteroid use 
A. Peak mass bone accrual occurs during puberty. $50 \%$ of lifetime bone mass is acquired during this important phase of adolescence.

\section{QUESTION 3}

What advice would you give as an emergency plan for extra corticosteroid use in a patient with suppressed hypothalamic pituitary adrenal axis, during a time of illness?

a) Double the current dose of corticosteroid

b) Triple the current dose of corticosteroid

c) No change in corticosteroid

d) Give an injection of hydrocortisone $50-100 \mathrm{mg}$, followed by 3 times maintenance corticosteroid for 3 days, double for a further 2 days

e) None, the patient does not require any steroids

\section{ANSWER 3}

D. Usual maintenance dose of corticosteroid for physiological replacement, if there is adrenal suppression, is calculated at $10 \mathrm{mg} / \mathrm{m}^{2} /$ day of hydrocortisone equivalent. Stress doses are double and triple this dose: up to $30 \mathrm{mg} / \mathrm{m}^{2} /$ day of hydrocortisone. In case of accident, emergency, major medical illness such as gastroenteritis or influenza, any surgical condition requiring general anaesthetic or any major fracture, IV/IM hydrocortisone (25-100mg depending on age of the child) should be administered and repeated $6^{\text {th }}$ hourly until recovery has taken place. The normal oral hydrocortisone dose should then be tripled for three days and doubled for a further two days. Education for emergency dosing for illness should be provided to families as part of a corticosteroid 'stress dose' management plan, when corticosteroid use continues for more than 6-8 weeks. (3).

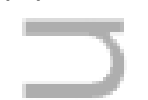

Addendum: Rapid weaning to physiologic levels at $10 \mathrm{mg} / \mathrm{m}^{2} /$ day hydrocortisone equivalent ( $2.5 \mathrm{mg}$ prednisolone $10 \mathrm{mg} \mathrm{HC}$ ) can be undertaken, followed by a slower rate, 
determined in part by age of the child, younger children improving more quickly. In general, 3-6 months of slow steroid reduction is required, by around $1 \mathrm{mg}$ prednisolone per change, with an overall change to hydrocortisone $(\mathrm{HC})$ when dose is $<4 \mathrm{mg} / \mathrm{m}^{2} /$ day, as $\mathrm{HC}$ has a shorter duration of action and is less suppressive of the adrenal. Once dose is around $4 \mathrm{mg} /$ day $\mathrm{HC}$, withdrawal of an evening dose can occur, followed by second daily cessation of morning dose. Finally, after 36 hours off corticosteroid, a morning cortisol should be checked, hoping for a level $>150 \mathrm{nmol} / / /$. If suppression continues, reinstitution of steroid with a slower weaning process needs to be undertaken.

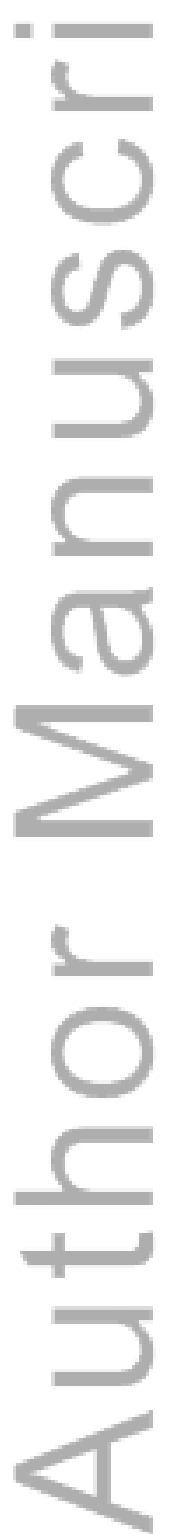

This article is protected by copyright. All rights reserved. 


\section{Bibliography}

1. Patt $\mathrm{H}$, Bandgar T, Lila A, Shah N. Management issues with exogenous steroid therapy. Indian journal of endocrinology and metabolism. 2013;17(Suppl 3):S612-7.2.

2. Canalis E, Mazziotti G, Giustina A, Bilezikian JP. Glucocorticoid-induced osteoporosis: pathophysiology and therapy. Osteoporosis international : a journal established as result of cooperation between the European Foundation for Osteoporosis and the National Osteoporosis Foundation of the USA. 2007;18(10):1319-28.

3. Liu D, Ahmet A, Ward L, Krishnamoorthy P, Mandelcorn ED, Leigh R, et al. A practical guide to the monitoring and management of the complications of systemic corticosteroid therapy. Allergy, Asthma, and Clinical Immunology : Official Journal of the Canadian Society of Allergy and Clinical Immunology. 2013;9(1):30.

4. Broersen LH, Pereira AM, Jorgensen JO, Dekkers OM. Adrenal insufficiency in corticosteroids use: systematic review and meta-analysis. The Journal of clinical endocrinology and metabolism. 2015:jc2015-1218.

5. Brown JJ, Zacharin MR. Proposals for prevention and management of steroidinduced osteoporosis in children and adolescents. Journal of paediatrics and child health. 2005;41(11):553-7.

6. Simm PJ, Johannesen J, Briody J, McQuade M, Hsu B, Bridge C, et al. Zoledronic acid improves bone mineral density, reduces bone turnover and improves skeletal architecture over 2 years of treatment in children with secondary osteoporosis. Bone. 2011;49(5):939-43.

7. Sidoroff M, Kolho KL Screening for adrenal suppression in children with inflammatory bowel disease discontinuing glucocorticoid therapy. BMC Gastroenterol.2014;14:51

8. Baek JH, Kim SK, Jung JH, Hahm JR, Jung J. Recovery of adrenal function in patients with glucocorticoids induced secondary adrenal insufficiency. Endocrinol Metab (Seoul) 2015 [Epub ahead of print]

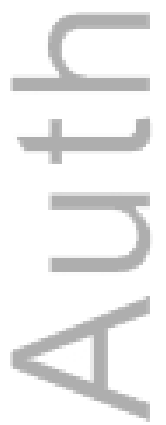


Figure 1. Serial photography illustrating progession of resolution of features of exogenous Cushing Syndrome secondary to glucocorticoid excess at presentation (left), and 6 months (right) following a controlled tapering steroid regime. Note excessive weight gain with truncal obesity, nuchal fat pad, gynaecomastia rounded plethoric face, striae, hypertrichosis, at presentation.

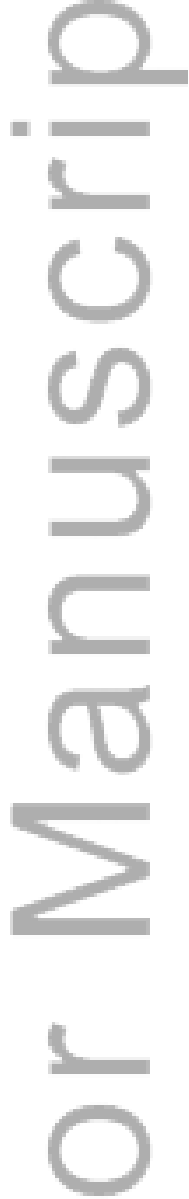

Figure 2: Growth chart highlighting atypical longitudinal growth. Incongruent increase of weight with faltering growth. Delayed bone seen. Height inconsistent with mid-parental height (MPH) expectation. 
Figure 3 Lateral view of the thoracolumbar spine. There is extensive abnormality of the vertebral endplates involving the thoracic and lumbar spine. These demonstrate anterior wedge fractures and biconcave compression fractures, with developing platyspondyly.

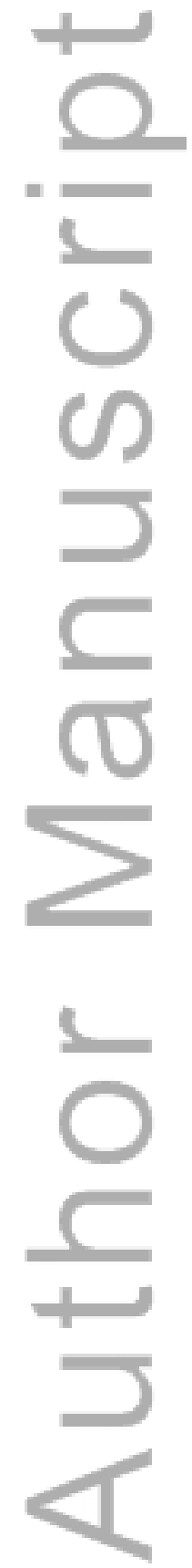

This article is protected by copyright. All rights reserved. 

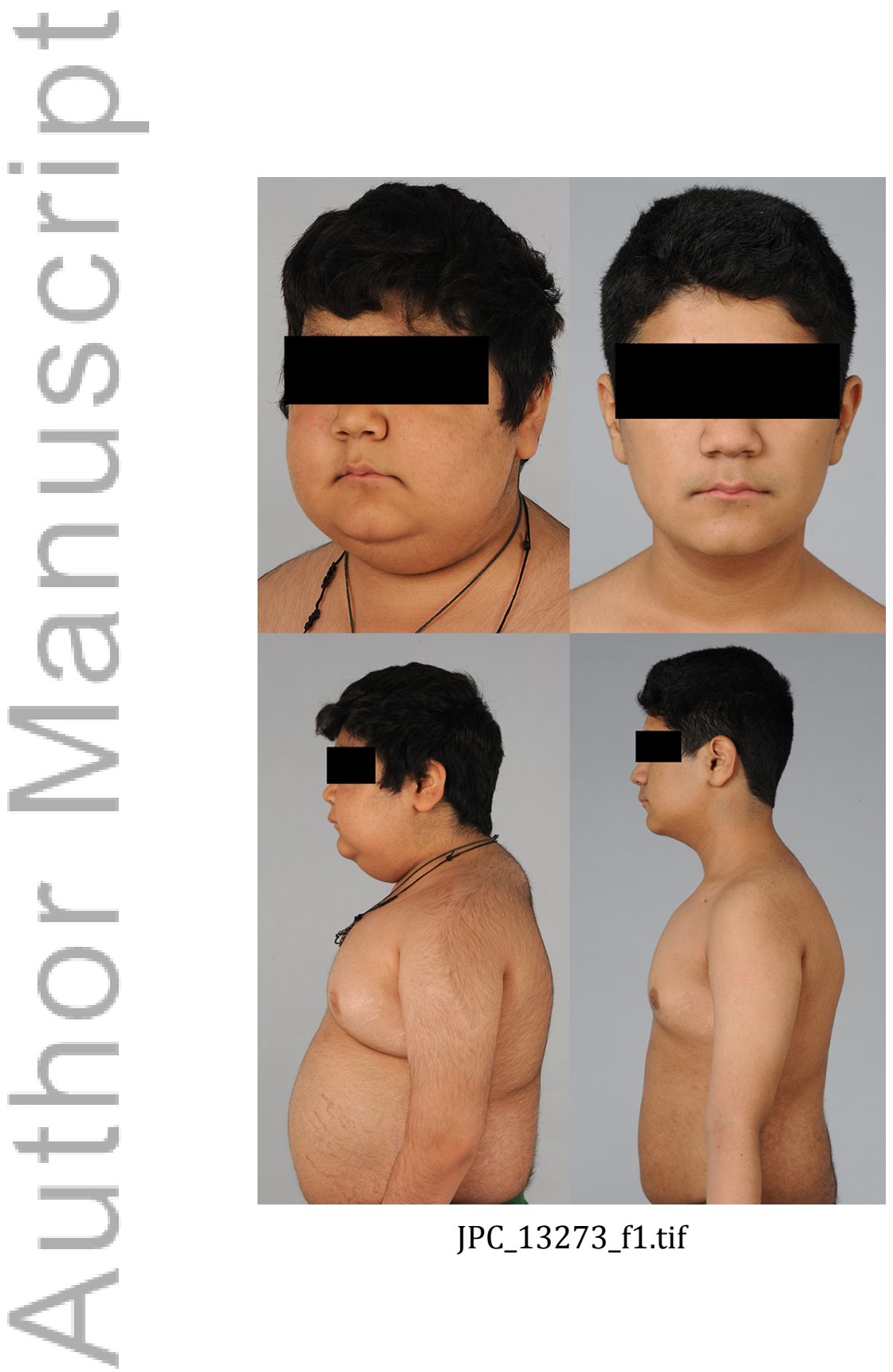

This article is protected by copyright. All rights reserved. 


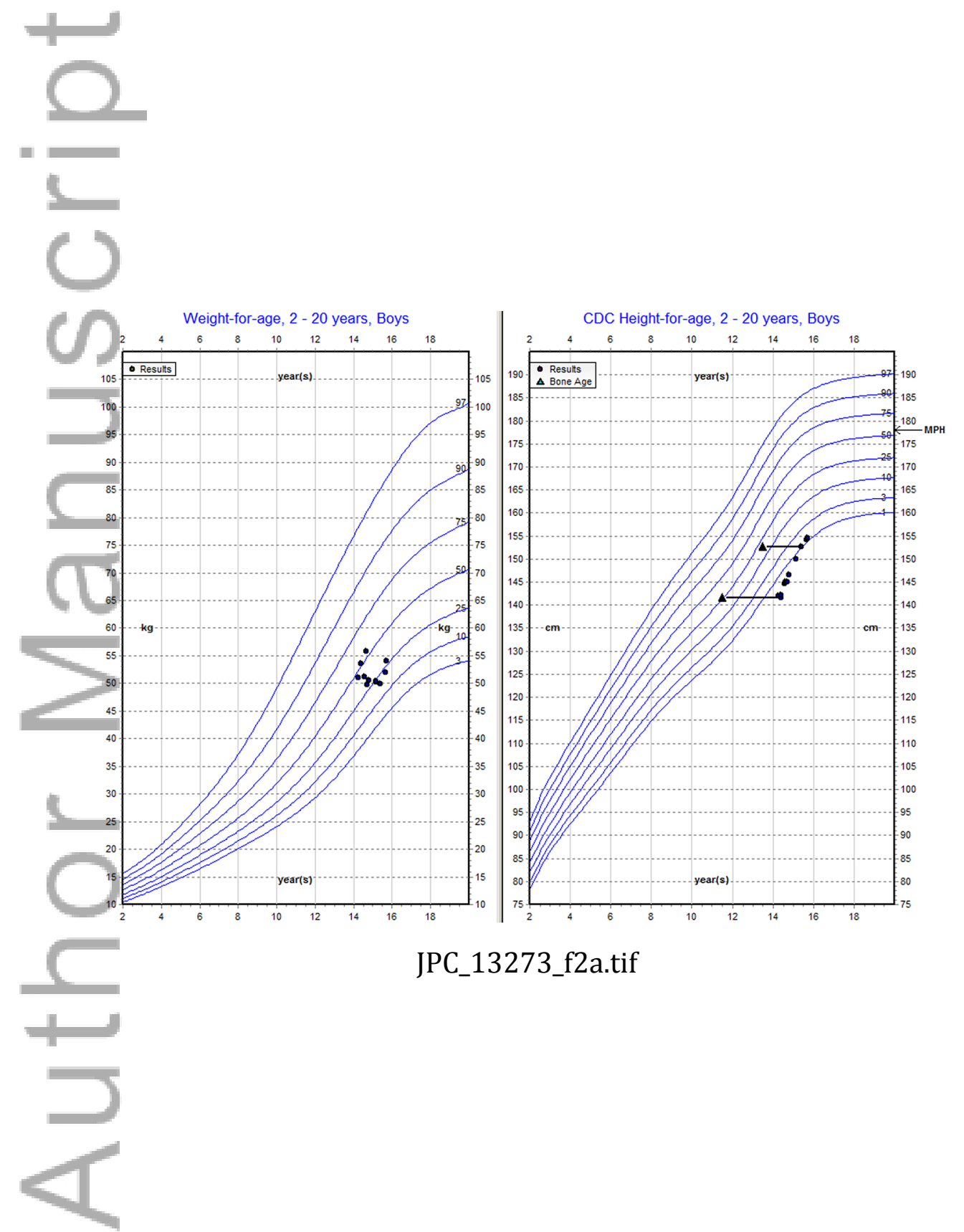

This article is protected by copyright. All rights reserved. 


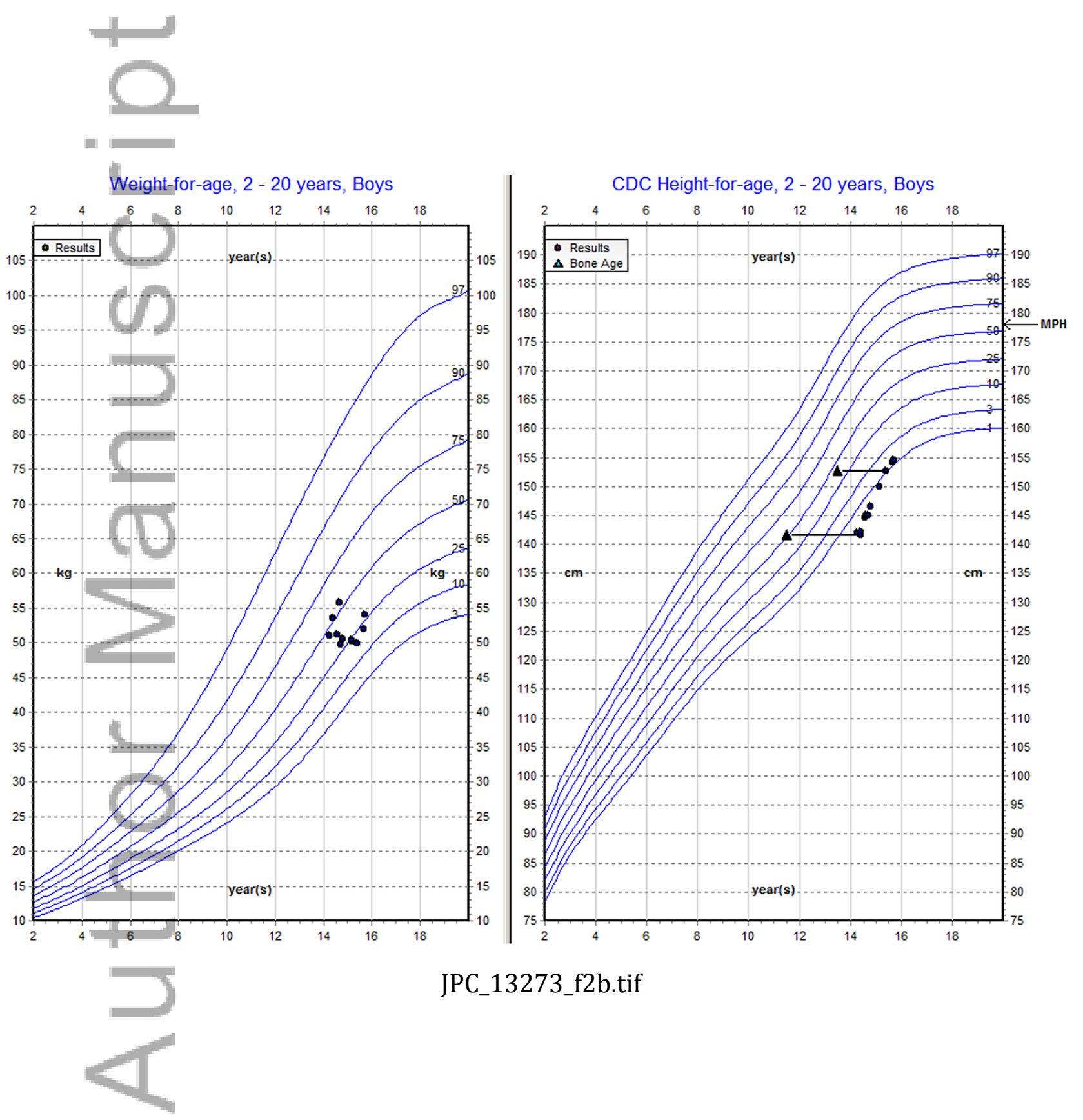

This article is protected by copyright. All rights reserved. 

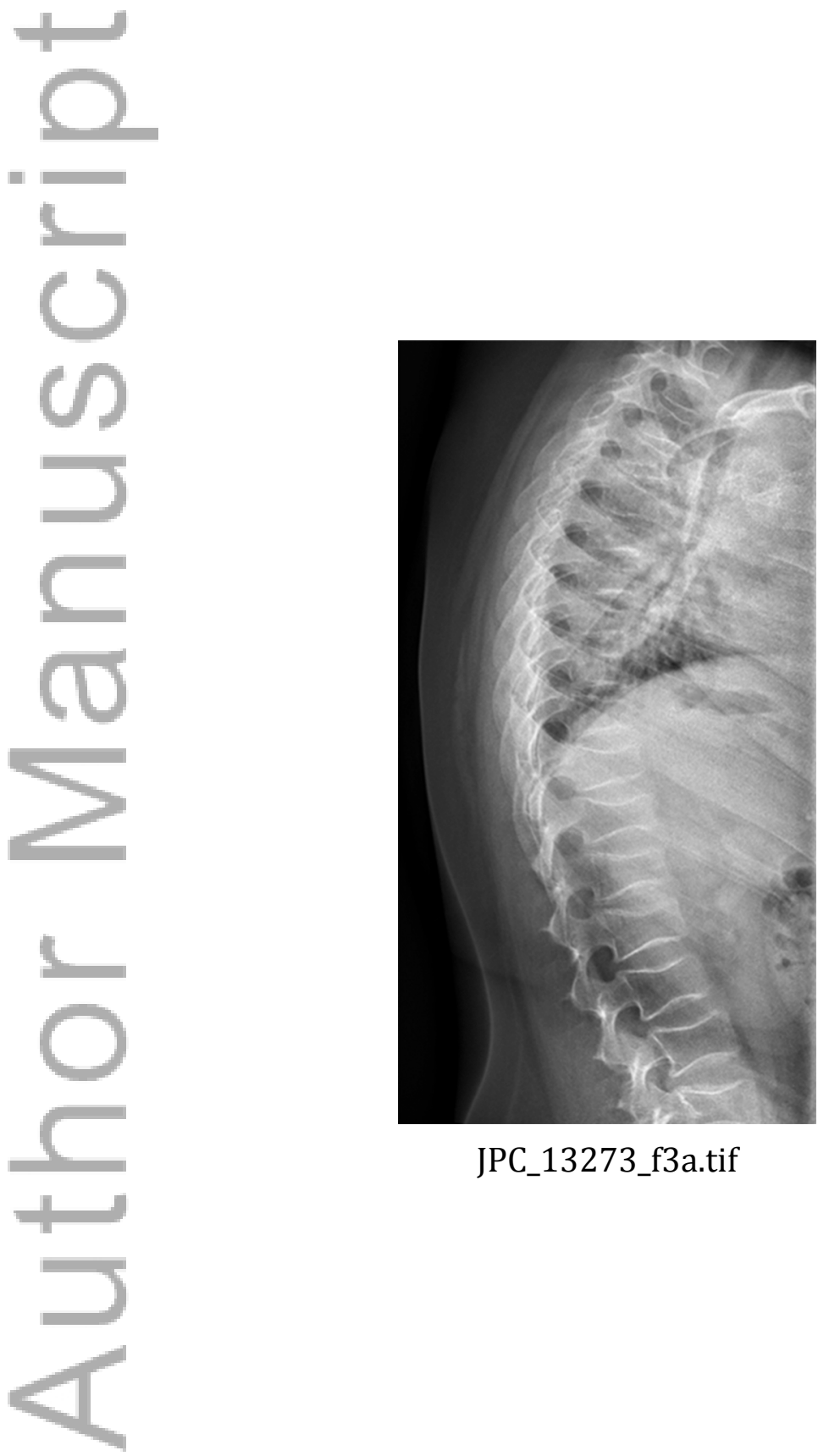

JPC_13273_f3a.tif

This article is protected by copyright. All rights reserved. 

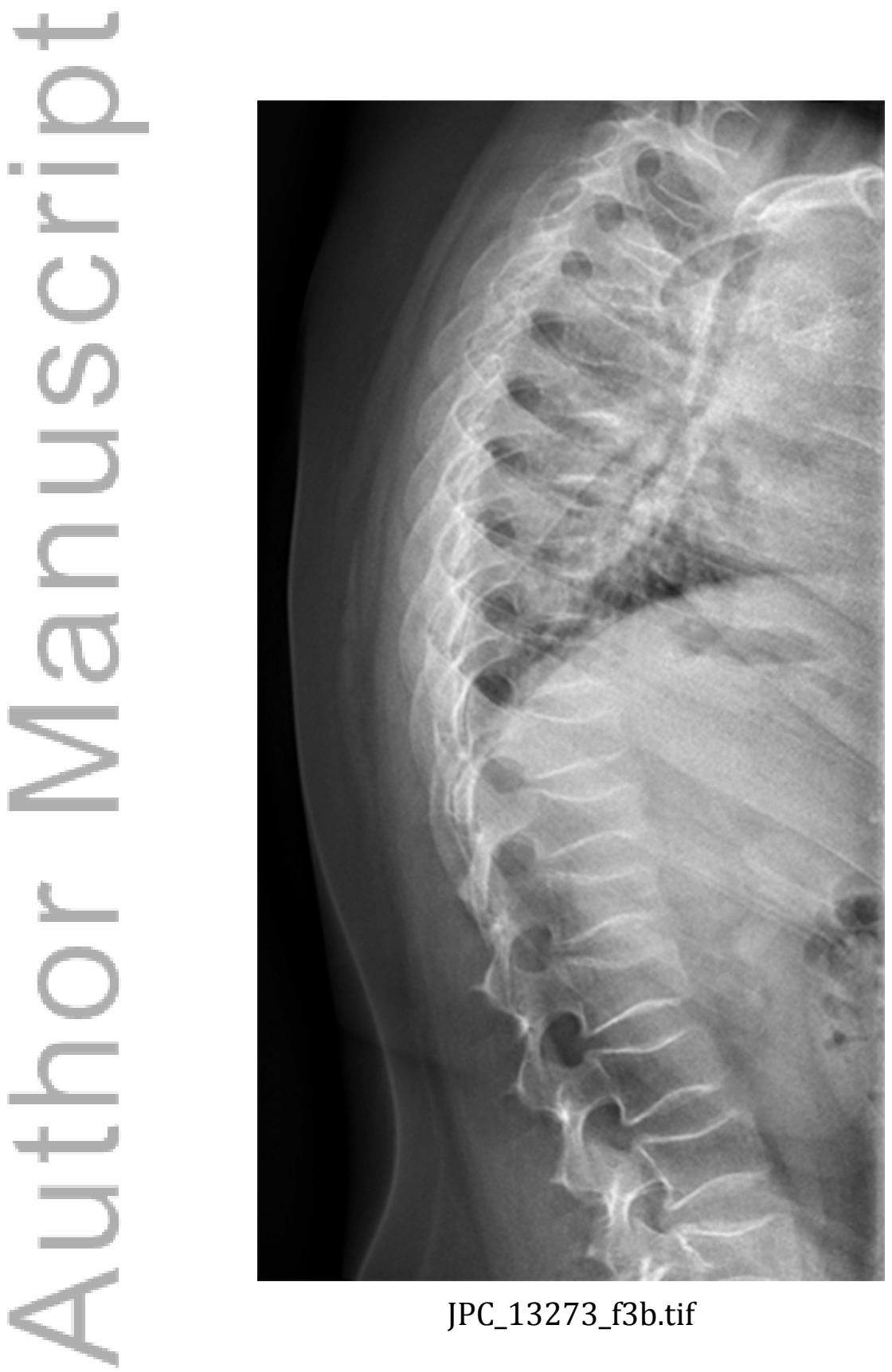

JPC_13273_f3b.tif

This article is protected by copyright. All rights reserved. 


\section{University Library}

\section{- M M I N E R VA A gateway to Melbourne's research publications}

Minerva Access is the Institutional Repository of The University of Melbourne

Author/s:

Messazos, BP;Zacharin, MR

Title:

Lessons from iatrogenic Cushing syndrome in children

Date:

2016-12-01

Citation:

Messazos, B. P. \& Zacharin, M. R. (2016). Lessons from iatrogenic Cushing syndrome in children. JOURNAL OF PAEDIATRICS AND CHILD HEALTH, 52 (12), pp.1106-1110. https:// doi.org/10.1111/jpc.13273.

Persistent Link:

http://hdl.handle.net/11343/291757 